\title{
Irrational use of antibiotics and the risk of diabetes in Ghana
}

\author{
Kwesi B. Mensah and Charles Ansah
}

Ghana Med J 2016; 50(2): 107-114 DOI: http://dx.doi.org/10.4314/gmj.v50i2.9

\begin{abstract}
Department of Pharmacology, Faculty of Pharmacy and Pharmaceutical Sciences, College of Health Sciences, Kwame Nkrumah University of Science and Technology, Kumasi, Ghana
\end{abstract}

Corresponding author: Professor Charles Ansah

Email: cansah.pharm@knust.edu.gh

Conflict of interest: None declared

\section{SUMMARY}

Epidemiological studies show clearly that Caesarean birth, perinatal or neonatal irrational antibiotic use is strongly associated with increased risk of obesity and diabetes in later life. Irrational use of antibiotics is a great global public health concern especially in developing economies like Ghana due to poor regulation on medicines. Unfortunately, this concern has been reduced to the fear of development of resistant organisms and the destruction of the world's limited range of antibiotics therapy at the expense of other insidious risks including the development of metabolic and atopic diseases. These risks however appear to have greater implications on public health systems of developing economies. Here, we review the ignored role of antibiotics in the global obesity pandemic and project the risk that it poses to the health system of a developing economy like Ghana.

Funding: Department of Pharmacology, College of Health Sciences, Kwame Nkrumah university of Science and Technology, Kumasi, Ghana

Keywords: Antibiotics, resistance, "thrifty gene", diabetes, Ghana

\section{INTRODUCTION}

The biggest challenge of health systems of many developing economies is the management of communicable diseases. Malaria still accounts for more than $40 \%$ of out-patients attendances in Ghana ${ }^{1}$ and takes a greater part of the health budgetary resources. Although communicable diseases remain the main threat to health of developing countries, non-communicable diseases kill more people in the developing world. ${ }^{2}$ In addition, it has been shown that rising incomes in these developing countries will stimulate rises in non-communicable diseases due to increased caloric intake, sedentary lifestyle, rapid nutrition transition and migration from rural to urban areas.

Nutrition transition, the shift from traditional diet to Western diets consisting more of processed foods, fat, and fructose, is fuelled by commercialization of the food trade $\mathrm{e}^{3,4}$ and many previously deprived regions of the world now have high accessibility to western diets. To these regions, commercialization of the food trade promotes food security but this may enhance the development of non-communicable diseases. Furthermore the deliberate introduction of high amounts of fructose into the diet is a potential source of concern as fructose unlike glucose is preferentially metabolized more into fat in the liver, leading to increased insulin resistance and visceral adipose tissue ${ }^{5,6}$ which are harbingers for diabetes and other metabolic syndromes.

Western lifestyle associated with increased alcohol and tobacco consumption ${ }^{7,8,9}$ partly due to aggressive marketing is a risk in the development of diabetes and other metabolic diseases. Subsequently, by the year 2030, non-communicable diseases will overtake communicable in many developing economies. Diabetes alone will increase by $150 \%$ in developing countries within that period. ${ }^{10}$

While the trends in diabetes in developing economies share some resemblance to trends seen earlier in the developed world, the projected absolute numbers of people to develop diabetes and other metabolic syndromes will overwhelm the health systems of these countries. Characteristically, diabetes and other metabolic diseases in developing economies affect people mostly in their productive years compared to much older people in the developed world. ${ }^{11,12}$ 


\section{Special Article}

Furthermore, low incomes, severe limitations of health resources and illiteracy will confound strategies that have worked in the developed world.

In view of the anticipated economic burden of therapeutic management of non-communicable diseases, there is the urgent need to use preventive strategies such as lifestyle changes and other public health interventions.

The precipitous rise in the prevalence of diabetes and other metabolic syndromes in the developing world, particularly in Southeast Asia, presuppose that perhaps the idea of high caloric diet (Western diet) consumption and sedentary lifestyle as the only cause may be too simplistic and insufficient to completely explain the trends. To support these assertions, several hypotheses have been proposed. Earlier suggestions had focused on racial and genetic susceptibility, ${ }^{13}$ typically initiated by the propounding of "Thrifting gene" hypothesis by $\mathrm{Neel}^{14}$ and other subsequent modifications.

However, other evidence suggests that common therapeutic agents like antibiotics may pre-dispose individuals to obesity and metabolic syndrome and may account partly for the rise in obesity-related diseases including cardiovascular and cerebrovascular accidents. Epidemiological studies show clearly that irrational antibiotic use is associated with increased risk of obesity, diabetes and asthma in later life. ${ }^{15}$ It appears that the average clinician may not be conscious of how a seemingly harmless action of inappropriate antibiotic usage can contribute to the global obesity pandemic and increased incidences of metabolic diseases. This review focuses on the apparent insidious role chronic and irrational antibiotic use may play in the increased obesity in the Ghanaian society using data from countries that are already suffocating under the stress of increased metabolic disorders.

Global changes in human body stature-Impact on health and the role of environmental chemicals

The physical condition of the human stature has being changing. Humans are now taller and bigger than they used to be two decades ago. In February 2014, the people's liberation army of China reported average increase in height and weight of Chinese soldiers over that of two decades ago. The US population has consistently grown taller from 1964. Epidemiological studies propose some health benefits for increased heights of a population, which include improved cardiovascular function ${ }^{16}$. However, this benefit will be nullified by the increased body weight. On the other hand, increased population height is associated with increased Ischemic Heart Diseases. ${ }^{17}$ Other data even suggest that shortness is associated with longevity and reduced risk of some cancers. ${ }^{17,18}$ Interestingly, some historic and current clinical data show that antibiotics may be influencing our bodies significantly which may be predisposing humans to diabetes, ischaemic heart diseases and cancers.

\section{Antibiotics and weight gain - a case for use in agri- culture}

Antibiotics form a backbone of the multimillion global poultry industry. First demonstrated by Jukes, ${ }^{19}$ antibiotics promote growth of vertebrates by enhancing the efficiency of conversion of feed to meat.

Several other scientists corroborated Jukes results and subsequently antibiotics were introduced into agriculture as growth promoters. ${ }^{20}$ Compared to human health, agriculture consumes more than $80 \%$ of all antibiotics produced. ${ }^{21,22,23,24}$ Antibiotic treated animals have altered gut anatomy and physiology including reduced intestinal weight and length, ${ }^{25,26}$ thinner intestinal epithelium, high efficiency in nutrient absorption and reduced metabolic demands of the gastrointestinal system. $^{21}$

It had been previously thought that the effect of antibiotics were due to the ability of sub-therapeutic doses to control subclinical infections. This was plausible because poultry raised in germ-free environments do not respond to the growth promoting effects of antibiotics but grow faster and more efficiently and exhibit feed efficiencies approaching those of antibiotic-treated poultry. ${ }^{27,28}$ However, it has been established that the enhanced growth, although independent on the kind of antibiotic used; was more pronounced in antibiotics that were rarely absorbed from the intestines. Consequently, conventional antibiotic mechanisms such as inhibition in specific microbial cellular or organelle functions have not been implicated but rather the effects of antibiotics in killing or inhibiting gut microflora growth.

Consistent in both humans and animals are the alterations in gut microflora of treated subjects. The current general consensus is that gut microflora; commonly referred to as the microbiome, were involved in programming the metabolism and the immunity of the individual $^{29,30}$ and early perturbations may affect size and immunity which may be very beneficial in agriculture but detrimental in human health.

\section{Antibiotics and the obesity pandemic}

It has been noted that babies born by caesarian section are more likely to be prone to obesity in later life than those born by natural means. ${ }^{31}$ The main explanation to this observation is that the acquisition of microorganisms from the birth canal of mothers appears to regulate the metabolism of the neonate. ${ }^{32}$ 


\section{Special Article}

Similarly, exposure to antibiotics during the first 6 months of life is associated with increase in body mass from 10 to 38 months ${ }^{28}$ and an increased risk of being overweight in children before age $7 .^{33}$ Several experiments, many unpublished because of ethical reasons, show that exposing children to antibiotics caused increases in weight.

Kalliomäki et al. ${ }^{34}$ has shown that $40 \%$ of overweight children had received antibiotics in infancy against 13\% in the normal-weight group by the age of 6 months. Although there is no available data on antibiotic consumption amongst Ghanaian children, it is known that at least in the US children are prescribed on average about one course of antibiotics every year, often for ear and chest infections. ${ }^{35}$ Similar trends are likely to be seen amongst urban and affluent Ghanaian children. Interestingly, more than half of antibiotics prescribed to children are deemed irrational and unnecessary.

Trends in antibiotic usage show increases and correlates very well with economic status of the population. It has been reported that the emerging economies of Brazil, Russia, India, China, and South Africa (BRICS) alone account for more the $70 \%$ for these rising trends in the past decade. ${ }^{36}$ This makes it difficult to exclusively evaluate the effects of antibiotics on human weight without high caloric diet, in particular fructose and sedentary lifestyles which are confounding factors. Although many of these studies have been in children, limited data from adults show similar patterns. In an unpublished experiment involving US Naval recruits, it was established that supplementation with antibiotics resulted in increased body mass. Thuny et al., $(2010)^{37}$ reported that treating adults with vancomycin and gentamicin combination, two antibiotics that are poorly absorbed from the intestines, for endocarditis was significantly linked to development of obesity within a year.

To understand the interaction between high caloric diet and antibiotic therapy, Cho et al. ${ }^{38}$ simulated experiments in mice where animals received a high caloric diet alone or in combination with antibiotics. Antibiotictreated mice gained twice the weight of untreated mice. Interestingly, the effects were greater amongst female animals than male. After antibiotic use, changes in the expression of gut microbial genes involved in metabolism of carbohydrates into short-chain fatty acids were observed with enhanced expression in genes involved in storing unused calories as lipids.

\section{The diabetes epidemic in China}

Type 2 diabetes has reached epidemic proportions in the general adult population in China. ${ }^{39}$ The National Dia- betes Research Group of China says that, just over two decades ago Type 2 was so rare in China that less than $1 \%$ of the population had the disease.

Today diabetes has reached alarming rates with more that $11 \%$ of the population having diabetes and approximately 500 million people having pre-diabetes; abnormally high hyperglycaemia but not high enough for a diagnosis. Interestingly, in China as in other Asian countries, obesity does not correspond so well with the development of diabetes; as diagnosis occurs at a much lower BMI of $23.7 \mathrm{~kg} / \mathrm{m}^{2}$ compared to $27 \mathrm{~kg} / \mathrm{m}^{2}$ in other populations. ${ }^{41,42}$ Researchers believe that there is a tendency among East Asians to accumulate belly fat (higher visceral adipose fat) which is a predisposing factor to the development of Type 2 diabetes. ${ }^{42}$ Genetic predisposition as well as high caloric diet and increasing sedentary lifestyle have been proposed to be the causes of the increases in diabetes. ${ }^{13}$ So far, no diabetic gene exclusive to Chinese or Asians has been reported. Although Western food consumption is growing rapidly amongst Chinese it still has not reached a huge proportion of the population to be solely responsible for these increases. Other East Asian countries that share similar genetic makeup and consuming high caloric diets as some Chinese are also experiencing increases in the incidence of diabetes but have not reached endemic rates. Moreover, globally there are countries that consume more calories and are less active than Chinese and yet diabetes has not reached such alarming rates. It is known that people living in cities and urban areas, tend to be less physically active partly because of mechanization of transport and white collar jobs and have high risk of obesity and diabetes. A Chinese study showed that diabetes prevalence differed in regions with economic status; however the prevalence of diabetes was similar between urban residents and rural residents in economically developed regions implying that there may be more to it than the presumed sedentary lifestyles. ${ }^{41}$

\section{China's abnormal antibiotic consumption}

Data on antibiotic consumption in China is unprecedented in the world. China has become the world's leading antibiotics consuming country, with an average consumption of 138 grams per person per year. Literally, the average Chinese now consumes ten times the antibiotic of an average American. Over $50 \%$ of outpatient's prescriptions from Chinese hospitals contain at least one antibiotic. ${ }^{51,52}$ This is in contrast to the US where only $15 \%$ of prescriptions have an antibiotic. ${ }^{53}$ According to data from the World Health Organization, up to $80 \%$ of all hospital admissions in China receive some type of antibiotic and broad-spectrum antibiotics and multiple antibiotic courses account for $58 \%{ }^{54}$ This figure is much higher than the international level of $30 \%$. 


\section{Special Article}

China along with four other countries currently account for more than $76 \%$ of the increase in global antibiotic consumption between 2000 and $2010 .^{36}$

Data from animal studies have shown that there is an association between antibiotic consumption and accumulation of visceral adipose fat. Visceral adipose fat is a risk in the development of diabetes. Some Chinese patients at diagnoses for diabetes have normal BMI but high visceral adipose fat.

\section{Diabetes in Ghana}

The earliest available post-independence data shows that prevalence was $0.2 \%$ of the population in $1964^{43}$ and this has increased steadily over the years. A Ghana Diabetes Association study showed that between 1990 and 2000 prevalence increased from $2-3 \%$ to $6.4 \%{ }^{44}$ Most of the increases occurred in urban centers with over $10.7 \%$ of the population having impaired glucose tolerance. The number of people with diabetes in Ghana is expected to double by $2030 .^{45,46}$ Additionally, it is reported that in Ghana due to some sociocultural practices and beliefs as well as rapid urbanization, there are indications that diabetes incidence in the Kumasi Metropolis, for example, amongst the adult population alone may be higher than many urban areas of SubSaharan Africa. ${ }^{47,48}$ Further projections by Mbanya et $a{ }^{49}$ indicate that diabetes-related morbidity and mortality in Ghana will increase dramatically in the coming years. The cost of managing diabetes in Ghana has increased steadily from $\$ 180-\$ 420$ in 2000 to $\$ 106-$ $\$ 638$ in 2007 per year. ${ }^{50}$ These figures exclude other cost in managing comorbidities such as dialysis in renal failure and hypertension. It is plausible that explosion in diabetes incidence in Ghana as pertains in South-East Asia may excessively increase the health budget, threaten the national insurance system and overwhelm Ghana's fragile economy. However, since approximately $90 \%$ of reported diabetes cases in Ghana are type 2, intensive public health education and appropriate interventions could salvage and reverse the current trend.

\section{Ghana's antibiotic consumption}

Due to poor drug regulation, data on antibiotic consumption patterns in Ghana is limited although antibiotics remain readily available in health facilities across the country and can easily be obtained without authorization from a qualified prescriber. Indeed the incidences of antimicrobial resistance and treatment failures give clear indications of irrational use of antibiotics. A report by Donkor et al. ${ }^{55}$ indicates that about $30 \%$ of tertiary students in Accra take an antibiotic within a month. In the same study $70 \%$ of respondents had self-medicated without a prescription. A study in the Cape Coast metropolis showed that over $70 \%$ of respondents obtained antibiotic without prescription. ${ }^{56}$ Consistently, amoxicil- lin, a broad spectrum antibiotic, accounts for more than $50 \%$ of antibiotics obtained without prescription in Ghana.

Respiratory conditions such as colds and coughs account for a chunk of the diseases for which antibiotics are used in Ghana. 55,56

Furthermore, with the recent introduction of pre-school in Ghana, and more mothers taking up jobs, baby respiratory infections are also expected to increase, which most invariably are managed with aggressive antibiotic therapy, even though many of these infections such as common cold are of viral origin and do not require antibiotic therapy. In line with this reasoning, infant antibiotic exposure may be underestimated.

\section{The Thrifty genotype explained with antibiotics}

Neel in 1962 attempted to explain why some people or populations were more susceptible to the development of diabetes through genetics and natural selection ${ }^{14}$. He proposed that early in the evolution of man when famine, as selective pressure, was predominant, inheritance of diabetes predisposing genes called "THRIFTY GENES" were beneficial in enhancing efficiency of conversion of food into fat for storage in anticipation of harder times. However these genes became a disadvantage in the modern world where famine is rare and food is readily available.

This hypothesis has been widely used to explain why some populations have high rates of diabetes. Unfortunately, years of research have not been able to identify the so called "THRIFTY GENES",57 and this has led to modifications and/or abandoning of the hypothesis. However, factoring in the role of antibiotics, whose use gained more grounds in health around the time the hypothesis was postulated, the hypothesis becomes more compelling. The evidence presented here so far shows that antibiotics enhance the efficiency of conversion of food to fat for storage which in the hypothesis is due to "THRIFTY GENES". Exposures to antibiotics promote expression of several genes involved in carbohydrate metabolism. It may be suggested that Neel's "THRIFTY GENES" are not more than genetic modification that occurs due to antibiotic exposure that promotes food utilization.

\section{Chinese and Ghanaian Health systems parallelism}

The Chinese health system is failing in its effort to control diabetes. It is said that for every new diagnoses of diabetes in China, two other people (70\%) remain undiagnosed. ${ }^{58,59}$ Ghana's health system cannot be said to be a miniature of the Chinese, however, there are some structural and policy driven features that resembles the Chinese system. 


\section{Special Article}

Most health facilities in China are owned and operated by the government. In order to enhance accessibility and affordability without compromising quality, the government (central, city, provincial) publishes the prices of services just like the National Health Insurance Authorities in Ghana. Hospitals in China are unable to meet their budgetary requirements and rely heavily on drug sales to meet their needs.

The Chinese government has reduced subventions to public hospitals and it is estimated that only $20 \%$ of hospitals income comes from the government. ${ }^{60,61,62}$ To stay afloat, facilities guided by profitability under provide, split or over-provide certain services to increase their revenue. ${ }^{63,64}$ Prescribers on their part are pressurized to prescribe medicines irrationally to meet the budget deficits and over half of hospital spending by patients is on pharmaceuticals. ${ }^{65}$ Like China, some pharmaceutical companies in Ghana also induce prescribers to prescribe their products to boost the sale of their products. ${ }^{66}$ National data show that $60 \%$ of hospitals' revenue is generated by selling drugs and $30-40 \%$ of drug consumption represented inappropriate utilization in China. ${ }^{67}$ In Ghana, government subventions are inadequate and insurance claims are delayed for a considerable period in the fiscal year. Hospitals are forced to rely on internally generated funds which may include increased drug sales.

Retail pharmacy practice is poorly developed in China and the practice of prescribing and dispensing is not distinct and clearly separated. Similarly in Ghana, The National Health Insurance Scheme does not decouple prescribing practices from dispensing practices. This breeds conflict of interest and promotes irrational antibiotic prescribing and usage. The National Health Insurance of Ghana like the Chinese government also does not pay dispensing fee as pertains in many countries ${ }^{67}$, but rather retail pharmacists and dispensers earn their income from the difference between the wholesale and retail prices. This does not motivate pharmacists to monitor irrational use of antibiotics since they stand to benefit from such practices.

The psyche of Chinese patients is such that they are likely to request for antibiotics from their General Physician even when in the opinion of the practitioner antibiotic use may be unnecessary. In Ghana, one of the objectives of the Ghana National Drug Programme (GNDP) is to promote the rational use of medicines. In spite of the efforts made by the programme, antibiotics are easily obtained from pharmacies without prescription. ${ }^{68}$ Drug regulation especially Class $\mathrm{A}$ and $\mathrm{B}$ drugs is a problem and several unlicensed and unaccredited persons dispense antibiotics to the general public. The
Food and Drugs Authority (FDA) in Ghana and the Ghana Pharmacy Council are under resourced to regulate the rational use of medicines. There are efforts by several non-governmental organizations to promote rational drug use. For example, the Antibiotic Drug Use, Monitoring and Evaluation of Resistance in Ghana (ADMER), a Ghana-Denmark initiative aims at building research capacity to help combat irrational antibiotic use. The efforts of government agencies including the FDA, GNDP and non-governmental organizations towards the rational use of antibiotics should be stepped up if Ghana is to avert the explosion of diabetes in the near future.

\section{CONCLUSION}

Ghana's economic growth has improved over the current decade. Rapid economic growth is associated with increased antibiotic consumption as well as increased metabolic and cardiovascular diseases. In view of the overwhelming evidence implicating antibiotic consumption to increased obesity and other metabolic related diseases, there is the urgent need to strictly enforce the regulations on the use of antibiotics in Ghana. With current trends, irrational antibiotic use in Ghana can only be expected to increase in the coming years. Therefore diabetes and other related metabolic diseases are expected to increase. The solution as has been emphasized elsewhere is lifestyle modification with active education for the promotion of rational antibiotic use. In practical terms, rational use of antibiotics will require that patients receive appropriate antibiotics, preferably narrow spectrum that meet their specific clinical needs, in the right doses for the appropriate duration at a reasonable cost. The long-term effects of irrational antibiotic use may be a price too costly for our fragile health system to bear. A multifaceted approach including education of clinicians, doctors, pharmacists, nurses and patients and adherence to rational prescribing and dispensing in Ghana as well as monitoring should provide the framework for the quest to reverse these trends.

\section{REFERENCES}

1. UNICEF. Malaria. UNICEF Ghana Fact Sheet. 2007

2. WHO.Global status report on non-communicable diseases. World Health Organization. Geneva: 2010.

3. Popkin BM, Lu B, and Zhai F. Understanding the Nutrition Transition: Measuring Rapid Dietary Changes in Transition Countries," Public Health Nutr 2002;947-953 


\section{Special Article}

4. Popkin BM. The nutrition transition and obesity in the developing world. $J$ Nutr 2001;131:871S-873S

5. Stanhope KL, Schwarz JM, Keim NL, et al. Consuming fructose-sweetened, not glucose-sweetened, beverages increases visceral adiposity and lipids and decreases insulin sensitivity in overweight/obese humans. $J$ Clin Invest 2009;119:1322- 1334

6. Stanhope KL, Havel PJ. Fructose consumption: recent results and their potential implications. Ann N Y Acad Sci 2010; 1190:15-24

7. Willi C, Bodenmann P, Ghali WA, Faris PD, Cornuz J. Active smoking and the risk of type 2 diabetes: a systematic review and meta-analysis. JAMA 2007;298: 2654-2664

8. Shetty PS. Nutrition transition in India. Public Health Nutr 2002;5:175-182

9. Koppes LL, Dekker JM, Hendriks HF, Bouter LM, Heine RJ. Moderate alcohol consumption lowers the risk of type 2 diabetes: a meta-analysis of prospective observational studies. Diabetes Care 2005; 28:719-725

10. WHO.Diabetes action now. Geneva: World Health Organization. Geneva 2004

11. Mudur G, "World Needs Fresh Research Priorities and New Policies to Tackle Changing Patterns of Chronic Disease," BMJ.2005; 331:7517-596

12. Misra A and Khurana L. Obesity and the metabolic syndrome in developing countries. J Clin Endocrinol Metab.2008;93:S9-30.

13. Mohan V, Balasubramanyam M, Radha V. Genomics and proteomics of Type 2 diabetes in Indians. J Assoc Physicians India; 2005; 53: 507-509.

14. Neel JV "Diabetes Mellitus: A "Thrifty" Genotype Rendered Detrimental by "Progress"?". Am. J. Hum. Genet. 1962; 14 (4): 353-62.

15. Flaherman V and Rutherford G W.A meta-analysis of the effect of high weight on asthma. Arch Dis Child 2006;91:334-339

16. Samaras TT and Elrick H. Height, body size and longevity. Acta Med Okayama 1999; 53:149-169.

17. Samaras TT and Elrick H. "Height, body size, and longevity: is smaller better for the humanbody?"The Western Journal of Medicine 2002;176 (3):206-208.

18. Chan CM and Oreglia A. California Life Expectancy: Abridged Life Tables for California and Los Angeles County, 1989-1991.Sacramento: Dept of Health Services; 1993.

19. Jukes TH. Antibiotics in animal feeds and animal production. Bioscience 1972;22: 526-534

20. Bunyan J, Jeffries L, Sayers JR, Gulliver AL and Coleman K. Antimicrobial substances and chick growth promotion: the growth-promoting activities of antimicrobial substances, including fifty-two used either in therapy or as dietary additives. $B r$. Poult. Sci.1977;18:283-294

21. Khachatourians GG. Agricultural use of antibiotics and the evolution and transfer of antibiotic-resistant bacteria. CMAJ 1998; 159 (9)

22. Witte W. Medical consequences of antibiotic use in agriculture. Science 1998; 279:996-7.

23. Levy SB. The challenge of antibiotic resistance. Sci Am 1998;278:46-53.

24. Feinmen SE. Antibiotics in animal feed: drug resistance revisited. $\mathrm{Am}$ Soc Microbiol News 1998;64:24-30.

25. Visek WJ. The mode of growth promotion by antibiotics. J.Anim.Sci. 1978;46:1447-1469

26. Postma J, Ferket PR, Croom WJ and Kwakkel RP. Effect of Virginiamycin on intestinal characteristics of turkeys. In: Proceedings of the 12th European Symposium on Poultry Nutrition (Kwakkel RP, and Bos JPM,eds). World's Poultry Science Association, Dutch branch. Het Spelderholt, Beekbergen, the Netherlands.1999;188.

27. Coates ME, Fuller R, Harrison GF, Lev M, and Suffolk SF.A comparison of the growth of chicks in the Gustafsson germ-free apparatus and in a conventional environment, with and without dietary supplements of penicillin. Br.J.Nutr.1963; 17:141150.

28. Forbes M, and Pank JT. Growth of germ-free and conventional chicks: effect of diet, dietary penicillin and bacterial environment.1959; J. Nutr. 67:6984.

29. Penders J, Thijs C, Vink C, Stelma FF, Snijders B, Kummeling I. Factors influencing the composition of the intestinal microbiota in early infancy. Pediatrics.2006;118: 511-521

30. Gronlund MM, Arvilommi H, Kero P, Lehtonen $\mathrm{OP}$, Isolauri E. Importance of intestinal colonisation in the maturation of humoral immunity in early infancy: a prospective follow up study of healthy infants aged 0-6 months. Arch Dis Child Fetal Neonatal Ed 2000; 83:F186-F192

31. Ajslev TA, Andersen CS, Gamborg M, Sorensen TI, Jess T. Childhood overweight after establishment of the gut microbiota: the role of delivery mode, pre-pregnancy weight and early administration of antibiotics. Int J Obes. 2011; 35:522-529.

32. Trasande L, Blustein J, Liu M, Corwin E, Cox LM, and Blaser MJ Infant antibiotic exposures and early-life body mass. Int J Obes. 2013. 37:16-23

33. Headley J, and Northstone K. Medication administered to children from 0 to 7.5 years in the Avon Longitudinal Study of Parents and Children (ALSPAC). Eur J Clin Pharmacol.2007;63: 189-195

34. Kalliomaki M, Collado MC, Salminen S, Isolauri E. Early differences in fecal microbiota composition 


\section{Special Article}

in children may predict overweight. Am J Clin Nutr 2008; 87: 534-538.

35. Sharland, MJ. The use of antibacterials in children: a report of the Specialist Advisory Committee on Antimicrobial Resistance (SACAR) Paediatric Subgroup Antimicrob. Chemoth. 2007; 60 ( 1), i15i26

36. Van Boeckel TP, Gandra S, Ashok A, Caudron Q, Grenfell BT,Levin SA, Laxminarayan R.(2014). Global antibiotic consumption 2000 to 2010: an analysis of national pharmaceutical sales data .The Lancet.Infectious Diseases.2014 (14): 8, 742-750

37. Thuny F, Richet H, Casalta JP, Angelakis E, Habib G, Raoult D. Vancomycin Treatment of Infective Endocarditis Is Linked with Recently Acquired Obesity. PLoS one.2010; 5(2):e9074

38. Cho I, Yamanishi S, Cox L, Methé BA, Zavadil J, Li K, Gao Z et al. Antibiotics in early life alter the murine colonic microbiome and adiposity. $\mathrm{Na}$ ture.2012;488, 621-626

39. Yang W, Lu J, Weng J, Jia W, Ji L, Xiao J, Shan Z, Liu J, Tian $\mathrm{H}$, et al Prevalence of Diabetes among Men and Women in China for the China National Diabetes and Metabolic Disorders Study Group. $N$ Engl J Med 2010; 362:1090-1101

40. National Diabetes Research Group. Diabetes mellitus survey of 300,000 in fourteen provinces and cities of China. Chin Med J. 1981;20:678-681

41. Yoon KH, Lee JH, Kim JW, Cho Y, Ko S, Zimmet $\mathrm{P}$, Son H.Epidemic obesity and type 2 diabetes in Asia. Lancet. 2006;368:1681-1688

42. Lear SA, Humphries KH, Kohli S, Chockalingam A, Frohlich JJ, Birmingham CL. Visceral adipose tissue accumulation differs according to ethnic background: results of the Multicultural Community Health Assessment Trial (M-CHAT). Am J Clin Nutr 2007;86:353-359.

43. Dodu SRA, de Heer N. GMJ. 1964;3:75

44. Amoah AGB, Owusu KO, Adjei S. Diabetes in Ghana: a community prevalence study in Greater Accra. Diabetes Research and Clinical Practice. 2002;56:197-205

45. Wild S, Roglic G, Green A, Sicree R, King H. Global Prevalence of Diabetes. Estimate for the year 2000 and projections for 2030. Diabetes Care 2004; 27:1047-1053

46. International Diabetes Federation. Diabetes Atlas http://www.idf.org/diabetesatlas/5e/the-globalburden

47. Amidu N, Owiredu W, Mireku E, Agyemang C: Metabolic syndrome among garage workers in the automobile industry in Kumasi, Ghana. J Medical and Biomedical Sciences 2012, 1(3):29-36.

48. Cook-Huynh M, Ansong D, Steckelberg RC, Boakye I, Seligman K, Appiah L, Kumar N, Amua- si JH: Prevalence of hypertension and diabetes mellitus in adults from a rural community in Ghana. Ethn Dis 2012, 22(3):347-352.

49. Mbanya JCN, Motala, AA Sobngwi E, Assah F K, Enoru S T. Diabetes in sub-Saharan Africa. 2010;375,(9733), 2254-2266

50. Aikins DA. Ghana's neglected chronic disease epidemic: a developmental challenge. GMJ. 2007; 41(4): 154-159.

51. Dong L, Yan H and Wang D. Antibiotic prescribing patterns in village health clinics across 10 provinces of Western China. J Antimicrob. Chemoth.2008;62, 410-415

52. Yin X, Song F, Gong Y, Tu X, Wang Y, Cao S, Liu J, Lu ZA. Systematic review of antibiotic utilization in China. J Antimicrob Chemother. 2013; 68(11):2445-2452.

53. Roumie CL, Halasa NB, Grijalva CG,Edwards KM,Zhu Y,Dittus RS,Griffin MR. Trends in antibiotic prescribing for adults in the United States-1995 to 2002. J Gen Intern Med.2005; 20: 697-702.

54. WHO. Using Indicators to Measure Country Pharmaceutical Situations. World Health Organization, 20 Avenue Appia, 1211 Geneva 27, Switzerland.2006.

55. Tagoe D, Attah C. A Study of Antibiotic Use and Abuse in Ghana: a case study of the Cape Coast Metropolis.The Internet Journal of Health. 2009;11(2).

56. Donkor ES, Tetteh-Quarcoo PB, Nartey P, Agyeman IO. Self-Medication Practices with Antibiotics among Tertiary Level Students in Accra, Ghana: A Cross-Sectional Study. Int J Environ Res Public Health. 2012 Oct; 9(10): 3519-3529

57. Southam L, Soranzo N, Montgomery SB, et al., Is the thrifty genotype hypothesis supported by evidence based on confirmed type 2 diabetes- and obesity susceptibility variants? Diabetologia 2009;52:1846-1851

58. Gao W, Dong Y, Nan H, Wang S, Ren J, Zhang L, Tuomilehto J, Qiao Q. A simple Chinese risk score for undiagnosed diabetes. Diabetic Medicine. 2010;27:3 274-281

59. Jia WP, Pang C, Chen L, Bao YQ, Lu JX, Lu HJ et al. Epidemiological characteristics of diabetes mellitus and impaired glucose regulation in a Chinese adult population: the Shanghai Diabetes Studies, a cross-sectional 3-year follow-up study in Shanghai urban communities. Diabetologia;2007;50:286-292

60. Henan Department of Health. The current status of the medical price management and its reform. Chinese Health Economics. 1993;2:33-4. 


\section{Special Article}

61. Zhou HZ. Health reform should be adapted to the transformation of the economy. Chinese Health Economics. 1993;6: 7-9.

62. Li XP. The marketization of health care. Chinese Hospitals Management. 1993;2: 5-7.

63. Liu X, liu Y, and chen N. The Chinese experience of hospital price regulation. Health Policy and Planning.2000; 15(2): 157-163.

64. State Council Research and Development Center, People's Republic of China. The evaluation and recommendation to Chinese healthcare reform: summary and key points. China Dev Rev. 2005;A01:1-14
65. Ying W. Memo on revised National Health Accounts for 1993. Washington, DC: The World Bank. 1996.

66. Dai D. A review of the health care reform. Chinese Health Economics. 1993. 2: 26

67. Reynolds L,and McKee M. Factors influencing antibiotic prescribing in China: An exploratory analysis. Health Policy.2009;90(1):32-36

68. Zhang R, Eggleston K, Rotimi V, and Zeckhauser RJ. Antibiotic resistance as a global threat: Evidence from China, Kuwait and the United States. Global Health 2006;2-6 